\title{
Metodologias simples para determinar em solos parcialmente saturados a envoltória de resistência \\ ao cisalhamento
}

\author{
-. YAMile VAlencia GonzÁlez ${ }^{1}$ \\ Jose CAMAPum de CARvalHo ${ }^{2}$ \\ GILSON GITIRANA ${ }^{3}$
}

\section{Resumo}

0 artigo propõe metodologias de laboratório simples para obter a envoltória de ruptura em solos para diferentes conteúdos de umidade. A primeira metodologia é baseada em ensaios de tração indireta de das amostras usadas para a definiç̧ão da curva característica do solo e o ensaio de cisalhamento direto saturado. Esta metodologia é avaliada numericamente a partir da distribuição do estado de tensões usando o modelo de elementos finitos em 3D. As outras metodologias consistem na combinação dos ensaios de cisalhamento direto em amostras saturadas e o ensaio de compressão simples, assim como da combinação do ensaio de compressão simples com o ensaio de tração indireta, junto com a curva característica. Estas metodologias têm como vantagem a simplicidade e economia, possibilitando a avaliação de parâmetros de resistência, para uma condição diferente à saturada, e que pode ser uma alternativa razoável quando os parâmetros de tensão não podem ser obtidos diretamente dos ensaios de cisalhamento com sucção controlada.

Palavras-chaves: Solos não saturados, Tração indireta, Cisalhamento direto, Compressão simples, Envoltória de resistência, sucção.

1 Universidad Nacional de Colombia. Medellín, Colombia.

2 Universidade de Brasilia. Brasilia, Brasil.

3 Universidade Federal de Goiás. Goiânia, Brasil.

Autor de correspondencia: Valencia González, Y. (Yamile): Facultad de Minas, Universidad Nacional de Colombia: Av. 80 \#\#65 - 223, Medellín, Colombia. Teléfono: 4255187. Correo electrónico: yvalenc0@unal.edu.co
Historia del artículo:

Artículo recibido: 22-XII-2017 / Aprobado: 30-V-2019

Disponible online: 3 de julio de 2019

Discusión abierta hasta marzo de 2021 


\section{Metodología simple para determinar en suelos parcialmente saturados la envolvente de resistencia al corte}

\section{Resumen}

En este artículo se proponen varios métodos de laboratorio simples para determinar la envolvente de ruptura en suelos no saturados. La primera metodología consiste en ensayos de tracción indirecta en muestras utilizadas para la definición de la curva característica del suelo, junto con la prueba de resistencia al corte directo saturado. Esta metodología se valida numéricamente a partir de la distribución del estado de tensiones, utilizando un modelo de elementos finitos en 3D. Las otras metodologías para determinar la envoltura de ruptura consisten en la combinación de pruebas de cizallamiento directo sobre muestras saturadas y la prueba de compresión simple; así como la combinación de las pruebas de compresión simple y tracción indirecta, definiendo también la curva característica. Tales metodologías tienen la ventaja de la simplicidad y economía, haciendo posible la determinación de parámetros de resistencia en condiciones diferentes a las saturadas, lo que puede ser razonable cuando los parámetros de resistencia no pueden obtenerse directamente de los ensayos de succión controlada.

Palabras claves: Suelos no saturados, Tracción indirecta, Corte directo, Envolvente de resistencia, Succión.

\section{Simple Methodology For Determining The Failure Envelope Of The Shear Strength Of Unsaturated Soils}

\section{Abstract}

This paper proposes several simple laboratory methodologies to determine the failure envelope in unsaturated soils. The first methodology consists on tests of indirect traction on samples used for the definition of the soil characteristic curve, together with the saturated shear strength test. This methodology is validated numerically from the distribution of stress state in the specimens, using a finite element model in 3D. The other methodologies for determining the rupture envelope consist of the combination of direct shear tests on saturated samples and the simple compression test; As well as the combination of the tests of simple compression and indirect traction, also defining the characteristic curve. Such methodologies have the advantage of simplicity and economy, making possible the determination of resistance parameters in unsaturated conditions, which may be a reasonable alternative when the strength parameters can not be obtained directly from the controlled suction tests.

Keywords: Unsaturated soils, indirect traction, Shear strength test, Envelope of the shear strength, Suction. 


\section{Introdução}

Na prática da engenharia é importante considerar a condição de não saturação do solo, a fim de aperfeiçoar os projetos quanto os aspectos econômicos e técnicos. Neste trabalho, pretende-se apresentar uma metodologia de avaliação dos parâmetros para determinar a envoltória de resistência ao cisalhamento dos solos em condição diferente à saturada, sendo esta ferramenta constituída de ensaios de laboratórios simples.

Essas metodologias se apresentam como alternativa às técnicas tradicionais de determinação de parâmetros de resistência que, para solos não saturados, são obtidos com trajetórias de sucção controlada.

Além da maioria dos laboratórios de mecânica dos solos não contar com os equipamentos necessários para realização de ensaios com trajetórias de sucção controlada, outro fato que pesa negativamente na sua utilização é o tempo relativamente longo requerido para a maioria dos ensaios da sucção controlada.

Este artigo propõe primeiro uma metodologia simples para avaliar o comportamento de solos não saturados, neste caso de dois solos diferentes de um perfil. A metodologia se baseia em ensaios de cisalhamento direto sobre amostras de solo saturadas e ensaios de tração indireta de corpos de prova cilíndricos usados para a definição da curva característica do solo. Embora outros tipos de ensaios possam ser usados, o método proposto tem a vantagem de trabalhar com os corpos de prova de solo não saturada usados para a determinação da curva característica de retenção de agua pelo o método do papel de filtro.

Portanto, o teor de umidade, o índice de vazios, a sucção e a resistência à tração não saturada são conhecidos para cada corpo de prova. Se o ângulo de atrito $\left(\phi^{\prime}\right)$ for determinado por meio de ensaios de cisalhamento sobre amostras saturadas, e supondo que este ângulo não varie com a sucção, então é possível estimar a coesão do solo na condição não saturada. Concluindo-se esta etapa, para cada valor de sucção matricial é possível determinar também ângulo de atrito $\left(\phi^{\mathrm{b}}\right)$. É importante ressaltar que, segundo Camapum de Carvalho \& Gitirana (2005), as alterações nos valores do ângulo de atrito dos solos tropicais não saturados, determinados por meio de ensaios de corte direto, são atribuídos ao modo como se interpreta o ensaio.

Os resultados experimentais foram avaliados numericamente por meio do programa de cálculo numérico FlexPDE, obtendo valores bastante próximos, refletindo que o método pode ser uma alternativa simples, rápida e econômica quando os parâmetros do solo não podem ser obtidos diretamente dos ensaios de cisalhamento com sucção controlada.

Tendo avaliado numericamente a primeira metodologia passou-se a testar a segunda, que consiste em combinar dois a dois, três ensaios diferentes (cisalhamento direto, tração diametral e compressão diametral), para a determinação dos parâmetros que definem a envoltória de ruptura do material de um tipo de solo. Uma das combinações consiste em unir os resultados do ensaio de cisalhamento direto saturado e o ensaio de tração diametral (como foi feito na metodologia anteriormente descrita), outra resulta do ensaio de cisalhamento direto saturado e compressão simples e a última consiste em unir os dados de tração diametral e compressão simples. Os corpos de prova usados na execução dos ensaios, tanto de tração como de compressão, apresentam valores de umidade conhecidos o que permite a partir da curva característica a determinação da sucção mátrica existente.

\section{Materiais e Metodologia}

Foram estudadas para a primeira metodologia duas camadas a $5 \mathrm{~m}$ e $11 \mathrm{~m}$ de profundidade de um perfil de solo localizado em Brasil - Brasília (Distrito Federal - Setor de Transporte Rodoviário e Carga Sul - Guará). 0 Distrito Federal está ubicado no Planalto Central do Brasil, limitado pelo paralelo $15^{\circ} 30^{\prime} \mathrm{S}$ ao norte, pelo paralelo $16^{\circ} 03^{\prime} \mathrm{S}$ ao sul, pelo Rio Preto ao leste e ao pelo Rio Desco- 
berto oeste. 0 Distrito Federal encontrasse numa região que geologicamente conta com um predomínio de ardósias, meta-arenitos, quartzitos e metarritmitos do Grupo Paranoá. Com relação aos solos no Distrito Federal predominam o Cambissolo e os Latossolos vermelhos-escuros e vermelhos-amarelos (Lima, 2003). Na atualidade o clima é caracterizado pela ocorrência de duas estações, entre outubro e abril, com clima chuvoso e quente, e de maio a setembro a temporada é fria e seca; variando as temperaturas entre $13^{\circ} \mathrm{C}$ como valor mínimo e $22^{\circ} \mathrm{C}$ como valor máximo e uma umidade relativa entre $11 \%$ como limite inferior e $75 \%$ como limite superior durante todo o ano. A pluviometria média anual varia entre $1500 \mathrm{~mm}$ e $2000 \mathrm{~mm}$ (EMBRAPA, 1978 apud Souza et al., 2004).

A primeira metodologia utilizada neste trabalho leva em conta várias etapas e ensaios como: a determinação por cisalhamento direto do ângulo de atrito em condições saturadas $\left(\phi_{c d}^{\prime}\right)$; preparação dos corpos de prova cilíndricos; ajuste da umidade da amostra para a definição da curva característica; determinação da sucção matricial dos corpos de prova; e ruptura dos corpos em ensaios de tração indireta sob compressão diametral. As dimensões e o peso dos corpos de prova para tração indireta são determinados antes do ensaio, e depois são definidas a umidade e o índice de vazios, este pelo método da balança hidrostática. Para a definição da curva característica de retenção de água, recomenda-se a adoção de trajetória mista pelo método do papel filtro, ou seja, partindo da umidade natural, umedecem-se e secam-se os corpos de prova que se requeiram para definir uma curva característica bem ajustada.

Por meio do ensaio de tração indireta sob compressão diametral, se obtém de forma indireta a resistência à tração do material $\left(\sigma_{3 \mathrm{t}}\right)$, ao aplicar uma carga de compressão na amostra ao longo de seu eixo, Figura 1 (Valencia et al., 2005).

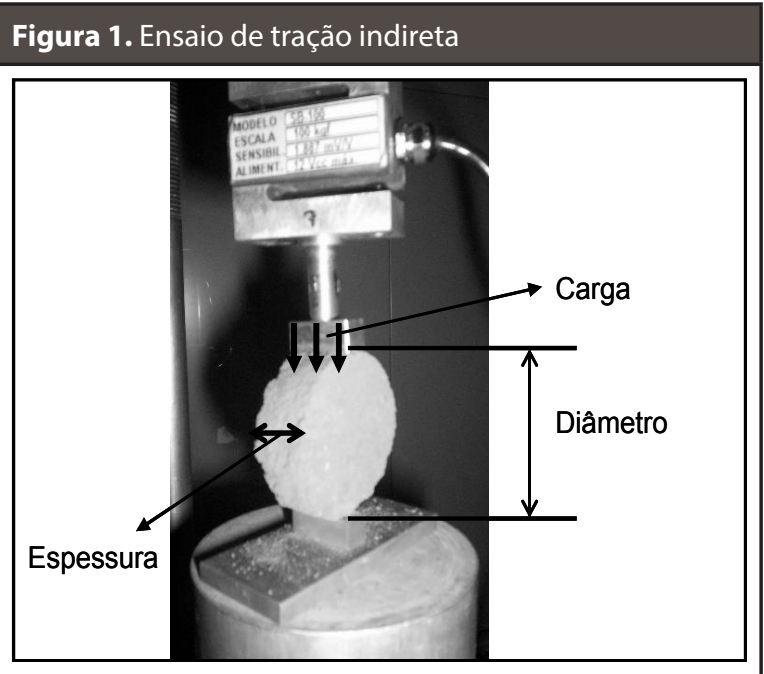

Segundo Carneiro \& Barcellos (1953), a ruptura é produzida por tração, e será dada por a Equação (1), onde (D) corresponde ao diâmetro da amostra, (L) à espessura da amostra e (P) à carga máxima de ruptura imposta.

$$
\sigma_{3 t}=\frac{-2 P}{\pi D L}
$$

Moraes, $\mathrm{T}$ et al. (2005), afirmam que o esforço máximo de tração é igual à resistência à tração uniaxial, e que o esforço de compressão $\left(\sigma_{1 \mathrm{t}}\right)$ pode ter um valor aproximado a três vezes o esforço de tração, segundo a teoria de elasticidade e o critério de ruptura de Griffith, o seja:

$$
\sigma_{1 t}=-3 \cdot \sigma_{3 t}
$$

Com o ângulo de atrito efetivo do solo saturado $\left(\phi_{\text {cd }}^{\prime}\right)$ e a resistência à tração, pode-se determinar a coesão total (c) a partir da seguinte expressão:

$$
\sigma_{3 t}=k_{p} \sigma_{1 t}+2 c \sqrt{k_{p}}
$$

Onde o valor da coesão total (c) seria:

$$
c=\frac{\sigma_{3 t}-k_{p} \sigma_{1 t}}{2 \sqrt{k_{p}}}
$$

0 valor de $k_{p}$ é dado pela Equação (5) 


$$
k_{p}=\frac{1+\operatorname{sen} \phi_{c a}^{\prime}}{1-\operatorname{sen} \phi_{c a}^{\prime}}
$$

Conforme apresentado na Equação (5), o valor do ângulo de atrito é aquele obtido do ensaio de cisalhamento direto saturado.

Os valores de coesão total (c) são plotados versus as sucções de cada corpo de prova o qual permitira determinar o ângulo de atrito $\left(\phi^{\mathrm{b}}\right)$ do material obtido a partir da equação de coesão total (6) para solos parcialmente saturados, onde:

$$
c=c^{\prime}+\left(u_{a}-u_{w}\right) \tan \phi^{b}
$$

Então,

$$
\phi^{b}=\tan ^{-1}\left(\frac{c-c^{\prime}}{\left(u_{a}-u_{w}\right)}\right)
$$

Por meio da análise numérica simulou-se o ensaio experimental de tração indireta. Para isso determinou-se: a geometria, em três dimensões (3D), utilizando-se apenas metade do formato, haja vista a simetria da amostra. Para as condições de contorno, tentou-se reproduzir as restrições de movimento e aplicação da carga distribuída na amostra, bem como o plano de ruptura para análise dos valores das tensões de tração e compressão. Conforme Figura 2.

\section{Figura 2. Geometria 3D da análise numérica}

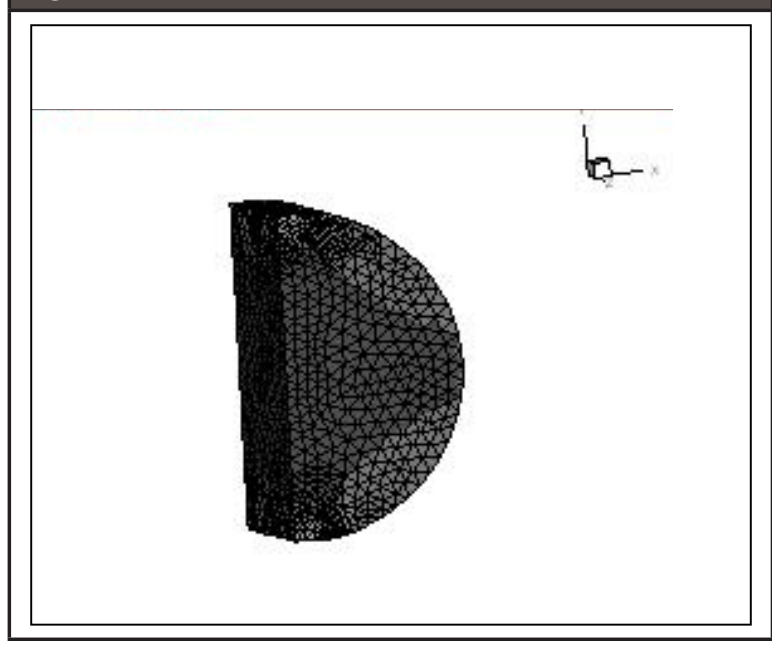

A partir destas configurações, com o auxilio do programa FlexPDE, que utiliza o Método dos ele- mentos finitos e malha auto-adaptável, calculou-se as tensões para o plano determinado, conforme ilustrado na Figura 3.

\section{Figura 3. Resultado da análise numérica}

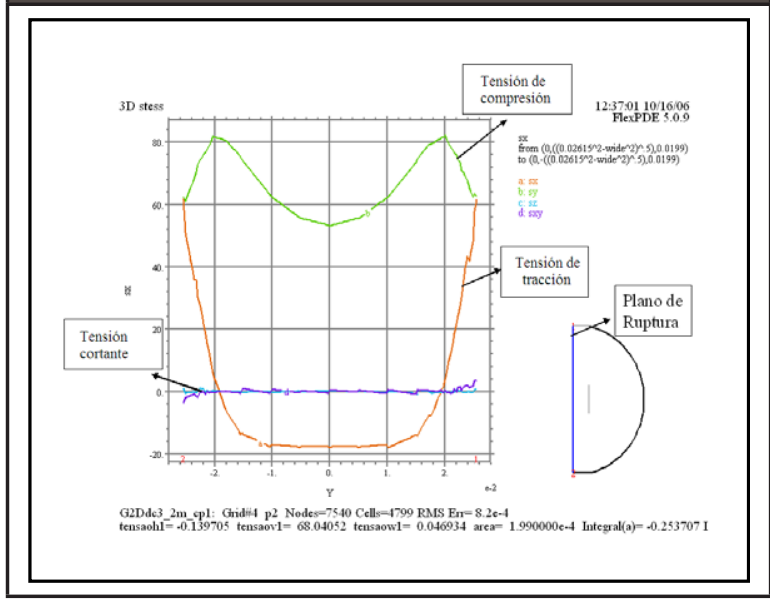

Após o cálculo das tensões, por meio da análise numérica, para cada uma das forças advindas do ensaio de tração indireta foi possível determinar uma relação entre força e tensão, de compressão e de tração, conforme pode ser observado na Figura 4.

\section{Figura 4. Relação tensão versus força}

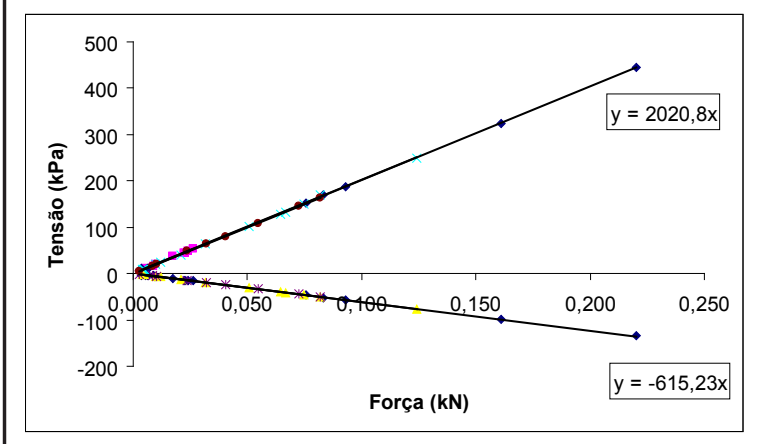

A partir da relação apresentada, podem-se obter os valores das equações para o cálculo das tensões por meio da força. Basta para isso utilizar a Equação 1, confrontada com as equações obtidas a partir do gráfico da Figura 4, portanto mantendo a relação tensão força em função da geometria. Obtêm-se então as Equações 8 e 9, válidas para qualquer valor de P, D e L (Santos, 2006). 


$$
\begin{gathered}
\sigma_{3 t}=-\frac{1,93 P}{\pi D L} \\
\sigma_{1 t}=\frac{6,33 P}{\pi D L}
\end{gathered}
$$

As Equações (8) e (9) propõem uma correção calibrada numericamente para a expressão do valor de resistência à tração calculada analiticamente de acordo com a Equação (1) e correspondentemente para à resistência à compressão $\left(\sigma_{1 \mathrm{t}}=-3^{*} \sigma_{3 \mathrm{t}}\right)$, devido a que a formulação analítica foi deduzida supondo-se um carregamento linear infinito sob condições de deformação plana, quando na realidade tem-se uma carga distribuída numa área finita, sob condições tridimensionais.

Na segunda metodologia o solo estudado se localiza na cidade de Brasília, DF- Brasil, especificamente no campo experimental do Programa de Pós-Graduação em Geotecnia da Universidade de Brasília. A posição geográfica é determinada pelas coordenadas $15^{\circ} 45^{\prime} 56^{\prime \prime}$ de latitude sul e $47^{\circ} 52^{\prime} 20^{\prime \prime}$ de longitude oeste. Nesta área o perfil característico está conformado por uma camada de solo laterítico vermelho argiloso (Bezerra, 2003). As amostras trabalhadas se encontram a $3 \mathrm{~m}$ de profundidade. Segundo Pastore (1996) citado por Bezerra (2003), até $5 \mathrm{~m}$ de profundidade neste perfil se tem um horizonte de solo residual laterítico, intemperado, conformado por uma argila arenosa vermelha escura. Este solo apresenta uma densidade relativa dos grãos, Gs, igual a 2,72, índice de vazios, e, igual a 1,2 e umidade natural, $\mathrm{w}$, igual a $23 \%$.

A primeira combinação para determinar os parâmetros de resistência e a envoltória de ruptura do solo é a mesma utilizada nos dois solos anteriores, que consiste como foi descrito, em combinar os ensaios de cisalhamento direto saturado e da resistência à tração diametral.

No caso da combinação do ensaio de cisalhamento saturado e da resistência à compressão simples, determina-se a resistência à compressão simples $\left(\sigma_{1 \mathrm{c}}\right)$ a partir da Equação (10), onde:

$$
\sigma_{1 c}=\frac{P}{A_{c}}
$$

com, $\mathrm{P}=$ Carga,

$$
\mathrm{Ac}=\text { Área corrigida }\left(A_{c}=A_{o} / 1-\varepsilon\right) \text {, }
$$

Ao = Área inicial,

$\varepsilon=$ Deformação

Sendo que:

$$
\sigma_{1 c}=k_{p} \sigma_{3 c}+2 c \sqrt{k_{p}}
$$

Assumindo-se $\sigma_{3 c}=0$, resulta:

$$
\sigma_{1 c}=2 c \sqrt{k_{p}}
$$

Substituindo a Equação (12) na Equação (3) se obtém:

$$
k_{p}=\frac{\sigma_{3 t}-\sigma_{1 c}}{\sigma_{1 t}}
$$

A coesão total (c) pode ser obtida a partir do valor de $k_{p}$ substituindo-se na Equação (12), então a coesão é igual a:

$$
c=\frac{\sigma_{1 c}}{2 \sqrt{k_{p}}}
$$

Para o ensaio de compressão junto com cisalhamento direto, a coesão total se calcula também a partir da Equação (14).

Deve-se ter cuidado que quando se usa a combinação do ensaio de tração ou de compressão com o do cisalhamento, o valor do $k_{p}$ é dado pela Equação (5), e que no caso da combinação de tração com compressão $k_{p}$ é calculado a partir da Equação (13).

0 ângulo de atrito $\left(\phi^{\mathrm{b}}\right)$ do material para as combinações tração-compressão e compressão-cisalhamento é obtido ao igual que na combinação tração-cisalhamento a partir da Equação (7).

\section{Resultados obtidos}

0 ensaio de cisalhamento direto em estado saturado permitiu encontrar para a camada a $5 \mathrm{~m}$ de profundidade um ângulo de atrito $\left(\phi^{\prime}{ }_{c d}\right)$ de $26^{\circ}$ e a coesão ( $c^{\prime}$ ) de $4,7 \mathrm{kPa}$. Na camada a $11 \mathrm{~m}$ de 
profundidade se obtivo um ângulo de atrito $\left(\phi_{c \mathrm{c}}^{\prime}\right)$ de $33^{\circ}$ e uma coesão (c') de $14 \mathrm{kPa}$.

Na Figura 5 se apresentam as curvas características das duas camadas do perfil de solo.

\section{Figura 5. Curva característica (Sucção vs Saturação Sr) a} $5 \mathrm{~m}$ e $11 \mathrm{~m}$

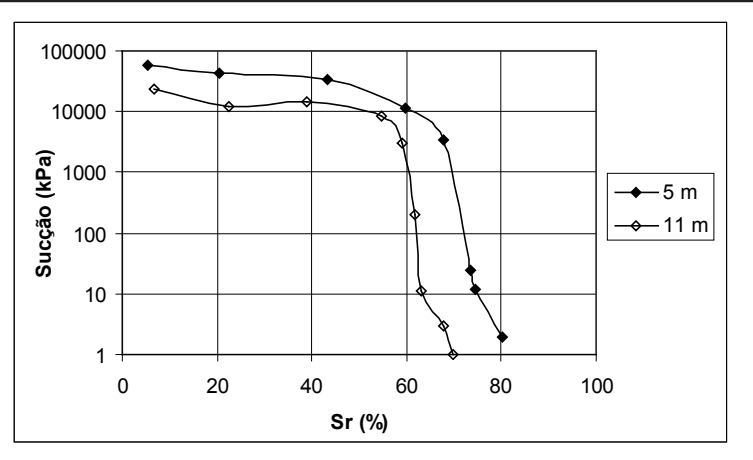

Conforme o citado anteriormente, com as amostras utilizadas para a determinação da curva característica dos solos foram executados os ensaios de tração indireta. Posteriormente foi calculada a resistência à tração e à compressão pela forma analítica, Equação (1) e (2), e pela fórmula corrigida numericamente, Equações (8) e (9). Da análise numérica encontrou-se que a resistência à tração corresponde a $\sigma_{3 t}=-\frac{1,93 P}{\pi D L}$ e a resistência à compressão a $\sigma_{1 t}=-3,28 \sigma_{3 t^{\prime}}$ mas estes resultados não diferem muito dos obtidos analiticamente, tal como se apresenta na Tabela 1.

Na Figura 6 no caso da resistência à tração $\left(\sigma_{3 \mathrm{t}}\right)$ calculada analiticamente com a sucção, pode se observar que as duas camadas apresentam um comportamento semelhante à tração. 0 valor da resistência à tração aumenta para incrementos significativos de sucção, atingindo seu máximo valor até o ponto da curva característica onde o solo não apresenta variações consideráveis de sucção. É claro que, a amostra encontra-se bastante seca apresentando trincas que fazem com que o material tenha uma forte queda na resistência a partir destes valores de sucção. Portanto, considera-se o ensaio representativo apenas até chegar ao pico da curva tração contra sucção. Deve-se ressaltar que este pico é atendido aproximadamente, quando a sucção passa a atuar no interior dos microporos, afetando por tanto, a estabilidade do agregado, mas tendo menor importância no comportamento mecânico do solo como um tudo.

TABELA 1. RESISTÊNCIA À TRAÇÃO $\left(\sigma_{3}\right)$ E À COMPRESSÃO $\left(\sigma_{1 t}\right)$ PELO MÉTODO ANALÍTICO E NUMÉRICO

\begin{tabular}{|c|c|c|c|}
\hline \multicolumn{4}{|c|}{$5 \mathrm{~m}$} \\
\hline \multicolumn{2}{|c|}{ Analítico } & \multicolumn{2}{|c|}{ Numérico } \\
\hline$\sigma_{3 t}(\mathrm{kPa})$ & $\sigma_{1 \mathrm{t}}(\mathrm{kPa})$ & $\sigma_{3 t}(k P a)$ & $\sigma_{1 \mathrm{t}}(\mathrm{kPa})$ \\
\hline$-50,9$ & 152,8 & $-52,0$ & 170,0 \\
\hline$-46,4$ & 139,1 & $-47,0$ & 153,0 \\
\hline$-134,7$ & 404,0 & $-135,0$ & 444,0 \\
\hline$-98,5$ & 295,4 & $-99,0$ & 325,0 \\
\hline$-56,8$ & 170,5 & $-57,0$ & 188,0 \\
\hline$-5,8$ & 17,5 & $-6,0$ & 20,0 \\
\hline$-3,7$ & 11,2 & $-4,0$ & 12,0 \\
\hline$-1,7$ & 5,2 & $-3,0$ & 11,0 \\
\hline \multicolumn{4}{|c|}{$11 \mathrm{~m}$} \\
\hline \multicolumn{2}{|c|}{ Analítico } & \multicolumn{2}{|c|}{ Numérico } \\
\hline$\sigma_{3 t}(\mathrm{kPa})$ & $\sigma_{1 \mathrm{t}}(\mathrm{kPa})$ & $\sigma_{3 t}(k P a)$ & $\sigma_{1 \mathrm{t}}(\mathrm{kPa})$ \\
\hline$-19,6$ & 58,7 & $-19,7$ & 64,8 \\
\hline$-33,5$ & 74,7 & -33 & 108,6 \\
\hline$-24,9$ & 100,6 & $-24,5$ & 80,5 \\
\hline$-44,5$ & 133,4 & $-44,3$ & 145,6 \\
\hline$-50,2$ & 150,7 & -50 & 163,4 \\
\hline$-14,4$ & 43,2 & -15 & 49,0 \\
\hline$-6,4$ & 19,1 & $-6,1$ & 20,1 \\
\hline$-5,1$ & 15,3 & $-4,9$ & 16,0 \\
\hline$-3,1$ & 9,3 & $-1,24$ & 4,21 \\
\hline
\end{tabular}

Figura 6. Tração versus sucção dos solos a $5 \mathrm{~m}$ e a $11 \mathrm{~m}$

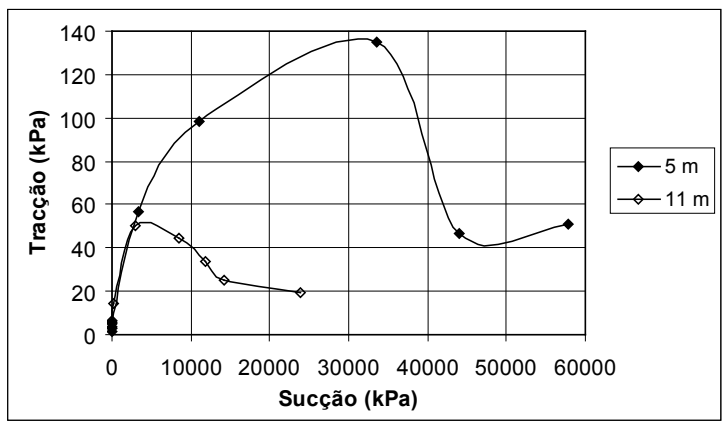


Posteriormente, com o ângulo de atrito determinado por meio do ensaio de cisalhamento inundado, foram calculadas tanto para os valores de tensão calculados analiticamente como para os numéricos, as coesões totais a partir da Equação 4. Como os valores de resistência à tração e à compressão resultaram bastante parecidos o valor da coesão pelos dois métodos é muito próximo, como apresenta a Figura 7.

\section{Figura 7. Cohesión total - método analítico y numérico}
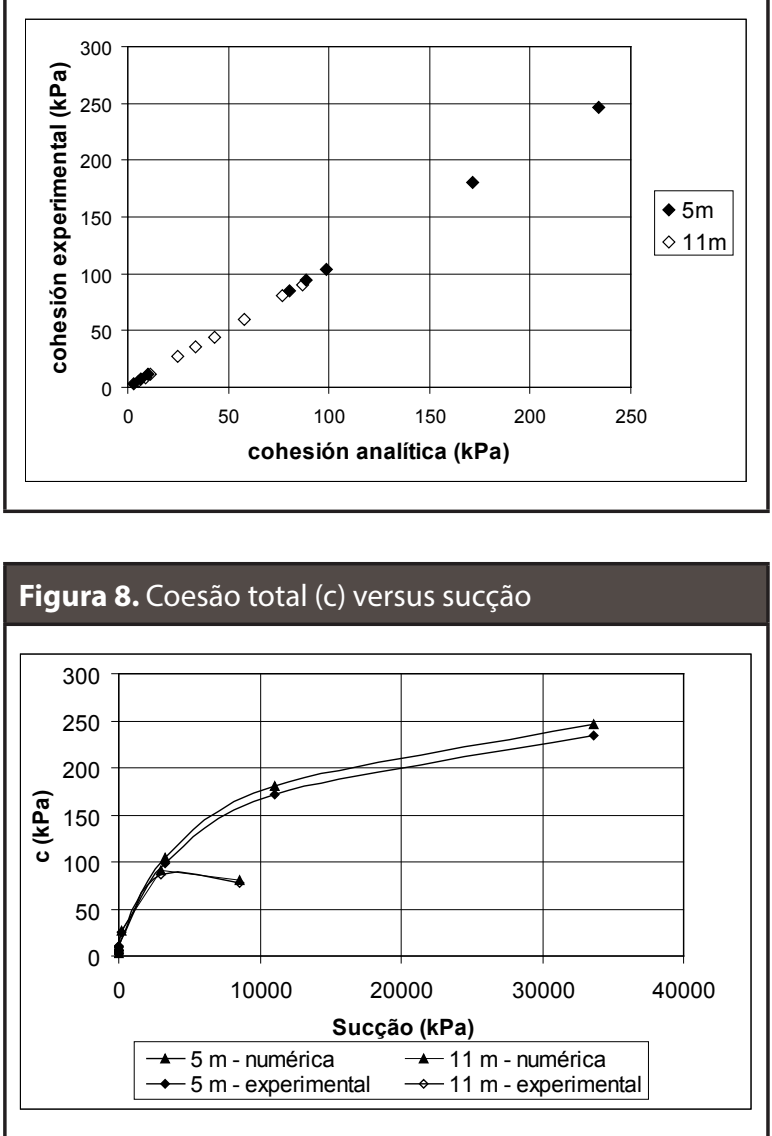

A Figura 8 permite determinar os ângulos de atrito $\left(\phi^{\mathrm{b}}\right)$ para cada camada de solo. Esta figura apresenta dois trechos de inclinação distinta, um trecho inicial, para o qual um pequeno aumento na sucção gera um grande aumento na resistência e um segundo trecho no qual um aumento na sucção não contribui significativamente para o aumento da resistência. Da Figura 9 a 12 são apresentados os trechos por separado.

\section{Figura 9. Determinação do ângulo de atrito $\left(\phi^{\mathrm{b}}\right)$ para o} trecho inicial da Figura 8 a 5 m

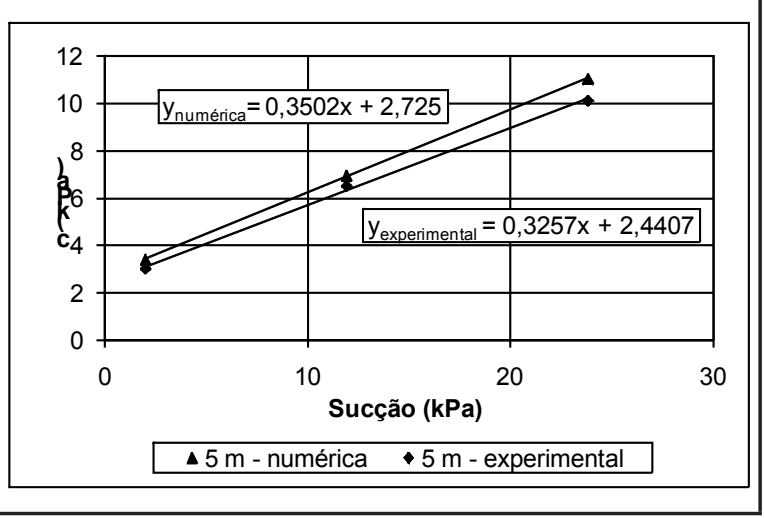

Figura 10. Determinação do ângulo de atrito $\left(\phi^{b}\right)$ para o segundo trecho da Figura 8 a 5 m

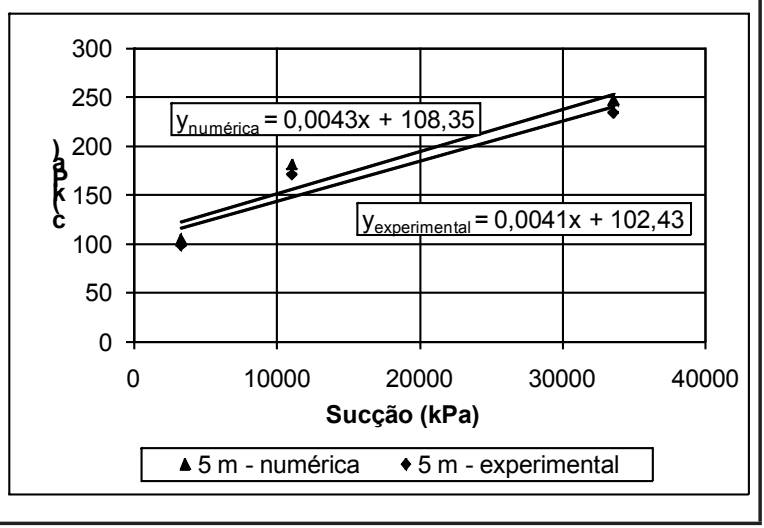

Figura 11. Determinação do ângulo de atrito $\left(\phi^{\mathrm{b}}\right)$ para o trecho inicial da Figura 8 a $11 \mathrm{~m}$

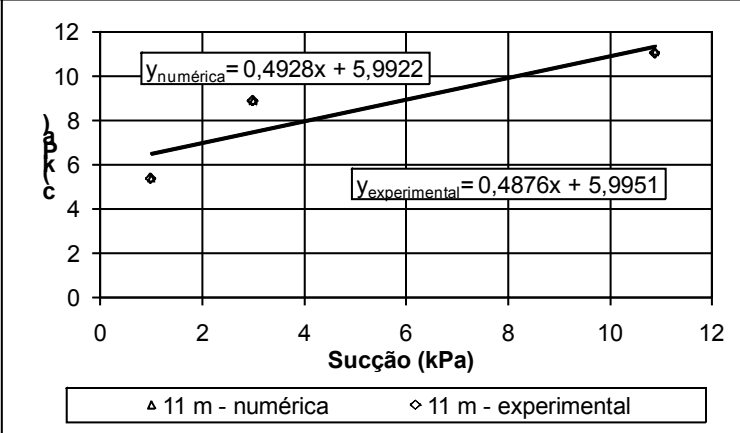


Figura 12. Determinação do ângulo de atrito $\left(\phi^{\mathrm{b}}\right)$ para o segundo trecho da Figura 8 a $11 \mathrm{~m}$

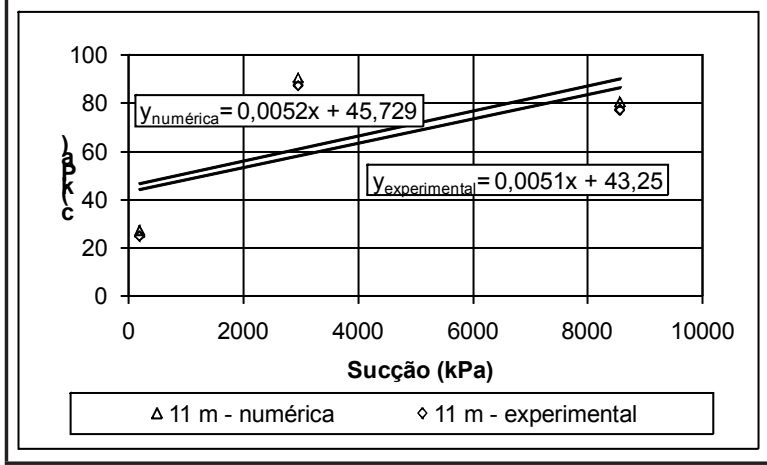

A Figura 13 apresenta os ângulos de atrito $\left(\phi^{\mathrm{b}}\right)$ para cada trecho pelos dois métodos. Pode-se ver que os valores do método analítico são bastante próximos ao método da análise numérica, o que confirma que a metodologia usada permite a determinação confiável dos valores de coesão total e ângulo de atrito $\left(\phi^{\mathrm{b}}\right)$. Além disso, pode-se ver que o valor do $\phi^{\mathrm{b}}$ aumenta a medida que diminui a sucção, ou seja, com o aumento na saturação, variando desde quase zero até um valor perto do ângulo de atrito $\left(\phi^{\prime}{ }_{\text {cd }}\right)$ no caso mais saturado, tal como previsto por Fredlund \& Rahardjo (1993) e constatado igualmente na pesquisa feita por Liu, S. H. \& Bai, F. Q. (2012), onde combinaram os ensaios de sucção com papel filtro e cisalhamento direto para diferentes umidades. Neste caso o $\phi^{\mathrm{b}}$ não chegou ao ângulo de atrito $\phi^{\prime}$, porque os materiais não alcançaram a 100\% da saturação (Figura 5).

Figura 13. Ângulo de atrito $\left(\phi^{\text {b }}\right)$ vs sucção primeira metodologia

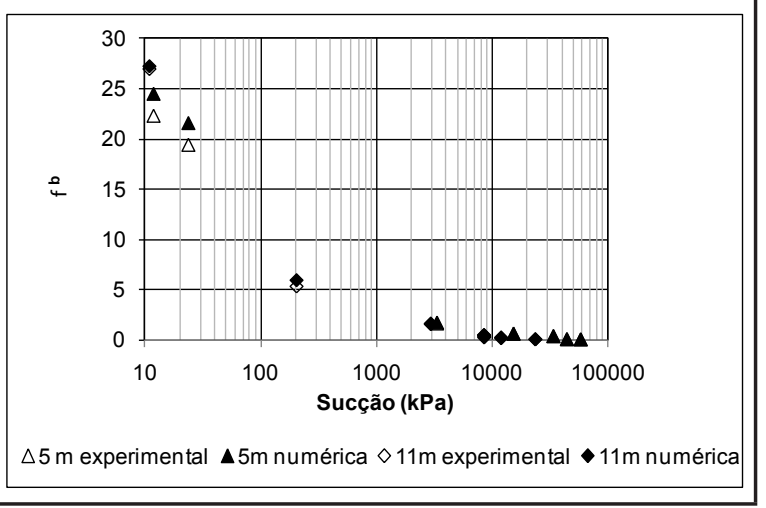

Com estes valores é possível desenhar a envoltória de ruptura do material a diferentes umidades, ou seja, para diversas sucções.

Para a segunda metodologia o solo estudado apresentou um $c^{\prime}$ e $\phi^{\prime}$ do cisalhamento direto de $5 \mathrm{kPa}$ e $27^{\circ}$ respectivamente.

A Figura 14 apresenta a curva característica de retenção de água do material, obtida tanto dos corpos submetidos a tração como a compressão.

\section{Figura 14. Curva característica do solo}

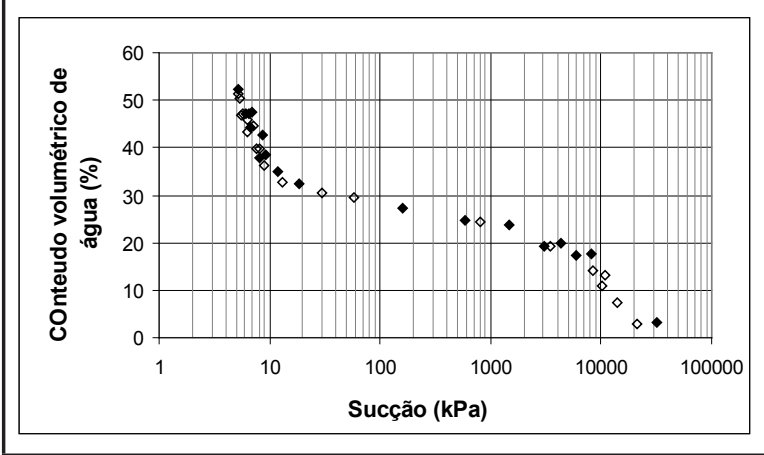

Posteriormente se realizaram os ensaios de tração e de compressão sobre as amostras que se encontravam a diferentes umidades, e a partir dos valores de resistência se determinaram as respectivas coesões do material nas diferentes umidades.

Na Figura 15 são apresentados os valores de coesão pelos três métodos. Pode-se observar que as três curvas apresentam um comportamento semelhante. Entretanto, para valores de sucção superiores a $10000 \mathrm{kPa}$ há uma inversão do comportamento, uma vez que as coesões obtidas pelo ensaio de compressão simples passam a ser menores que os obtidos pelas outras duas técnicas. Isso se deve ao aparecimento de fissuras verticais que controlam a ruptura diminuindo o valor da coesão.

Por outro lado, o fato de a coesão obtida pelo ensaio de compressão simples ser maior que das outras técnicas, para valores menores que $10000 \mathrm{kPa}$, deve-se a consideração de uma única medida de tensão a qual é uniforme em toda a amostra, o que não acontece no ensaio de tração. 
A Figura 15 mostra também que o valor da coesão total vai aumentando com a sucção até chegar a um valor máximo, o qual coincide nos três casos para uma sucção de $5280 \mathrm{kPa}(\mathrm{w}=14 \%)$. Para uma umidade menor que $14 \%$, a coesão começa a diminuir, uma vez que não é o solo que comanda a ruptura, mas as fissuras geradas pelo ressecamento do material.

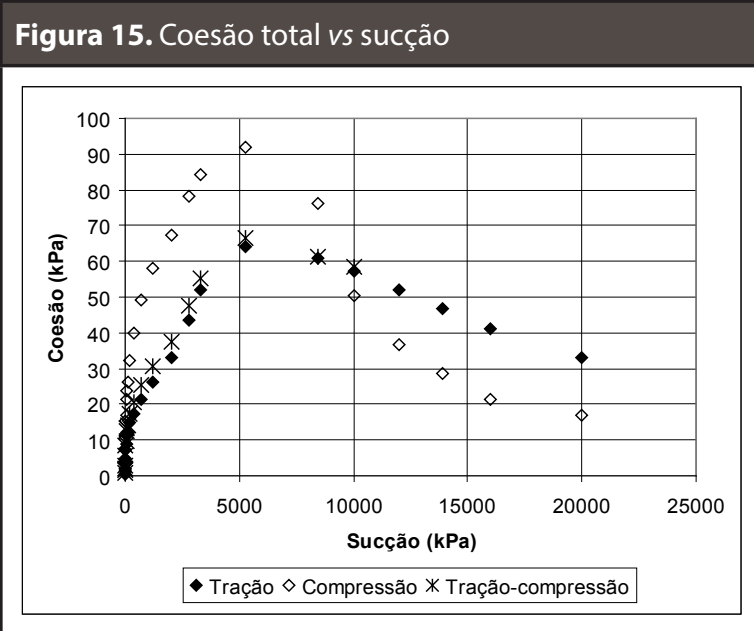

Finalmente são determinados os ângulos de atrito $\left(\phi^{\mathrm{b}}\right)$ para os três métodos, os quais são apresentados na Figura 16 em função da sucção do material.

\section{Figura 16. Ângulo de atrito $\left(\phi^{b}\right)$ vs sucção}

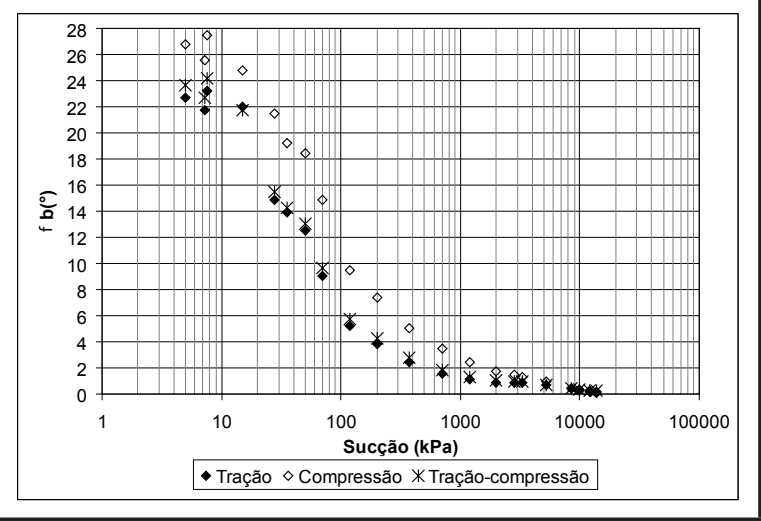

Da Figura 16 pode-se ver que o valor do $\phi^{\mathrm{b}}$ aumenta a medida que diminui a sucção, ou seja, com o aumento na saturação, variando desde quase zero até um valor perto do ângulo de atrito $\left(\phi^{\prime}=27^{\circ}\right)$ no caso mais saturado (90\%), tal como aconteceu nos outros solos. De maneira equivalente com estes valores é possível desenhar a envoltória de ruptura do material a diferentes umidades, ou seja, para diversas sucções.

\section{Conclusão}

- Comparando as três metodologias utilizadas pode-se afirmar que a metodologia que junta o ensaio de tração e o ensaio de compressão é a mais confiável, uma vez que esta não precisa do valor do ângulo de atrito $\left(\phi_{c d}\right)$ para determinar os parâmetros de resistência, enquanto nas outras metodologias propostas o cálculo de $k_{p}$ requer o valor de $\left(\phi_{c \mathrm{~d}}\right)$ obtido no ensaio de cisalhamento direto, sendo este constante.

- A validação numérica se mostra como uma ferramenta importante para comprovar resultados adotando teorias analíticas que se afastam um pouco das condições reais do material.

- É possível aplicar a teoria dos solos não saturados em solos tropicais de forma simples e prática, permitindo aperfeiçoar os projetos geotécnicos.

- Os ensaios apresentados para a obtenção dos parâmetros de resistência de solos não saturados mostraram resultados satisfatórios para a determinação da envoltória de ruptura do material de forma simples e econômica.

- Como os solos estudados são bastante rígidos, as mudanças na poro-pressão da água durante o ensaio de tração, foram considerados depreciáveis para conteúdos de umidade relativamente baixos. Embora, a metodologia proposta no futuro, deveria se realizar com sucção controlada para verificar esta consideração.

\section{Referências}

Bezerra - Mota, N. M. (2003). Ensaios avançados de campo na argila porosa não saturada de Brasília, tese (Doutorado em Geotecnia), Brasil, Universidade de Brasília, Faculdade de Tecnologia, Departamento de Engenharia Civil e Ambiental, pp. 335. Disponível 
em www. geotecnia.unb.br, [Consultado 22 de junho de 2011].

Camapum de Carvalho, J. \& Gitirana, G.Jr. Considerações sobre parâmetros de resistência de solos tropicais, II Simpósio Sobre Solos Tropicais e Processos Erosivos no Centro-Oeste, Goiânia-G0, 27-29 de outubro de 2005, pp. 183-191.

Carneiro, F. L. L. B. \& Barcellos, A. (1953). Résistance à la traction dês bétons. Bulletin Rilem (1), 13, pp. 97 108.

Fredlund, D.G.; Rahardjo, H. (1993). Soil Mechanics for Unsaturated Soil, New York, USA, John Wiley \& Sons, Inc., pp. 293-296.

Lima- Cruz, M. (2003). Degradação físico-química e mineralógica de maciços junto às voçorocas, tese (Doutorado em Geotecnia), Brasil, Universidade de Brasília, Faculdade de Tecnologia, Departamento de engenharia civil e ambiental, 336 pp. Disponível em www. geotecnia.unb.br, [Consultado 22 de junho de 2010].

Liu, S. H. \& Bai, F. Q. (2012). Measurement of the Shear Strength of an Expansive Soil by Combining a Filter Paper Method and Direct Shear Tests. Geotechnical Testing Journal, Vol. 35, No. 3, Sep, 451-459pp. [Online], www.astm.orgwww.astm.org, [Consultado 25 de novembro de 2017]

Moraes, T. R.; Nunes, A. L. L. S.; Lacerda, W. A. Resistência ao cisalhamento de dois solos coluvionares lateríticos através de ensaios de: compressão diametral e cisalhamento direto. IV Conferência Brasileira sobre Estabilidade de Encostas, Salvador Bahia, Brasil, 0406 de setembro de 2005, pp. 193-204.

Santos-Albuquerque M.A. (2006). Influência das condições de tensão e fluxo tridimensional na estabilidade de um talude em solo não saturado, dissertação (Mestrado em Geotecnia), Brasil, Universidade de Brasília, Departamento de Engenharia Civil e Ambiental. 204 pp. Disponível em www. geotecnia.unb. br, [Consultado 22 de julho de 2011].

Souza, E. R. A., Abílio de Carvalho, O. e Fontes, R. (2004). Evolução geomorfológica do Distrito Federal. Brasil. EMBRAPA, 122, 56 p. [online]. Disponível em: http:// repositorio.unb.br/bitstream/10482/16150/1/ ARTIGO_EvolucaoGeomorfologicaDistritoFederal. pdf. [Consultado 20 de junho de 2011].

Valencia, Y.; Márquez, M.A.; Camapum, J.; Villaraga, M.R. (2005). La meteorización y los mecanismos de inestabilización de taludes naturales en suelos residuales metamórficos. IV Conferência Brasileira sobre Estabilidade de Encostas, Salvador Bahia, Brasil, 04-06 de setembro de 2005, pp. 315-328.

\section{PARA CITAR ESTE ARTÍCULO / TO REFERENCE THIS ARTICLE / PARA CITAR ESTE ARTIGO /}

Valencia González, Y.; Camapum de Carvalho, J.; Gitirana, G. (2019). Metodologias simples para determinar em solos parcialmente saturados a envoltória de resistência ao cisalhamento. Revista EIA, 16(32), Julio-Diciembre, pp. 4353. [Online]. Disponible en: https://doi.org/10.24050/reia. v16i32.1218 